\title{
Short communication: Volatile profile of matured Tronchón cheese affected by oxytetracycline in raw goat milk
}

\author{
P. Quintanilla, ${ }^{1} \odot$ K. A. Hettinga, ${ }^{2} \odot$ M. C. Beltrán, ${ }^{1} \odot$ I. Escriche, ${ }^{3} \odot$ and M. P. Molina ${ }^{1 *} \odot$ \\ ${ }^{1}$ Institute for Animal Science and Technology, Universitat Politècnica de València, Camino de Vera, s/n 46022, València, Spain \\ ${ }^{2}$ Dairy Science and Technology Group, Chair of Food Quality and Design, Wageningen University, P.O. Box 17, 6700 AA Wageningen, \\ the Netherlands \\ ${ }^{3}$ Food Technology Department, Institute of Food Engineering for Development, Universitat Politècnica de València, Camino de Vera, s/n 46022, \\ València, Spain
}

\section{ABSTRACT}

The presence of antibiotics in milk destined for cheese production may affect the biological processes responsible for the formation of volatile compounds, leading to alterations in the characteristic cheese flavor expected by consumers. The aim of this study was to evaluate the effect of the presence of oxytetracycline in goat milk on the volatile profile of ripened cheeses. Traditional mature Tronchón cheeses were manufactured from raw goat milk spiked with different concentrations of oxytetracycline $(50,100$, and $200 \mu \mathrm{g} / \mathrm{kg}$ ). Cheese made from antibiotic-free goat milk was used as control. We analyzed the residual amounts of the antibiotic and the volatile profile of the experimental cheeses on a fortnightly basis during maturation using liquid chromatography tandem mass spectrometry and then solid-phase microextraction followed by gas chromatography-mass spectrometry. Our results suggested that oxytetracycline was widely transferred from milk to cheese: drug concentrations in the cheeses were 3.5 to 4.3 times higher than those in raw milk. Although the residual amounts of oxytetracycline significantly decreased during maturation (88.8 to $96.5 \%$ ), variable amounts of residues remained in cheese matured for 60 $\mathrm{d}(<10$ to $79 \mu \mathrm{g} / \mathrm{kg})$. In general, the presence of oxytetracycline in goat milk did not affect the volatile profile of Tronchón cheeses; volatile profile was significantly modified by ripening time. Still, the presence of oxytetracycline residues in cheeses ripened for $60 \mathrm{~d}$ could be of great concern for public health.

Key words: goat cheese, oxytetracycline, antibiotic residue, volatile profile

Received February 19, 2019.

Accepted February 1, 2020.

*Corresponding author: pmolina@dca.upv.es

\section{Short Communication}

In Mediterranean and Eastern European countries, goat milk is used mainly for cheesemaking, and demand has grown in the last decade because of the particular taste, nutritional value, and great variety of traditional cheeses. Cheese flavor is one of the most important organoleptic criteria for consumer acceptance, and it is the result of a complex balance between volatile and non-volatile chemical compounds. Biochemical processes such as glycolysis, lipolysis, and proteolysis are the main pathways for producing aromatic compounds such as alcohols, aldehydes, carboxylic acids, esters, ketones, and others during ripening (McSweeney and Sousa, 2000; Delgado et al., 2010). It is generally agreed that the presence of antibiotic residues in milk-aside from their negative implications for consumer healthaffect technological cheesemaking processes because they can inhibit the activity of the raw milk microflora and the starter cultures employed in the dairy industry (Katla et al., 2001). Thus, the liberation of enzymes could be altered and modify the production of aromatic compounds in matured cheese. One of the most widespread broad-spectrum antibiotics used in dairy goats is oxytetracycline, prescribed mainly to treat mastitis and urinary tract and enteric infections (Attaie et al., 2015). Oxytetracycline treatment could be the cause of antibiotic residues in milk if good farming practices are not correctly applied, especially related to the withdrawal period. In the European Union, the regulatory levels or maximum residue limits (MRL) for all tetracyclines in milk, including oxytetracycline, have been fixed at $100 \mu \mathrm{g} / \mathrm{kg}$ (European Union, 2010). In the European Union and other countries where qualitycontrol programs have been implemented, raw milk is routinely screened for antibiotic residues. Microbial inhibitor tests are usually applied in milk quality-control laboratories; they are able to detect $\beta$-lactam antibiotics at or below MRL but cannot suitably detect other veterinary drugs such as quinolones and tetracyclines 
at safety levels (Sierra et al., 2009; Beltrán et al., 2015). In farms and dairies, receptor-binding assays are commonly applied only to screen for $\beta$-lactam residues in goat milk, and they often do not detect other veterinary drugs such as tetracyclines. In less industrialized countries where no routine control of antibiotics in goat milk is implemented, the risk of antibiotic residues in the milk supply is increased. Studies investigating the effect of such substances in milk on cheesemaking and the organoleptic characteristics of the ripened cheese are very scarce (Cabizza et al., 2017; Quintanilla et al., 2019). The objective of this work was to evaluate the effect of different concentrations of oxytetracycline in raw goat milk on the volatile profile of Tronchón cheese during ripening.

We performed 3 trials of mature Tronchón cheese at the pilot plant of Universitat Politècnica de València (València, Spain) using Murciano-Granadina raw goat milk from the Universitat Politècnica de València experimental herd. For each cheese trial, $200 \mathrm{~kg}$ of milk was divided into 4 vats containing $50 \mathrm{~kg}$ each. Three of the vats were spiked with oxytetracycline (O4636; Sigma-Aldrich, Madrid, Spain) at different antibiotic concentrations closely related to the MRL: $50 \mu \mathrm{g} / \mathrm{kg}$ (0.5 MRL), $100 \mu \mathrm{g} / \mathrm{kg}(1 \mathrm{MRL})$, and $200 \mu \mathrm{g} / \mathrm{kg}(2$ MRL). A fourth vat was not spiked and was used as a control. We analyzed the chemical composition of the milk used for cheese production using a MilkoScan FT6000 (Foss, Hillerød, Denmark), and mean values ( \pm standard deviation) were as follows: $14.71 \pm 0.37 \%$ total solids, $5.37 \pm 0.19 \%$ fat, $3.98 \pm 0.22 \%$ protein, and $4.63 \pm 0.07 \%$ lactose. We made traditional semihard Tronchón goat cheese from the raw milk following the cheesemaking procedure reported by Quintanilla et al. (2019). Ten cheeses were obtained from each vat, and they were sampled in duplicate at $0,15,30,45$, and $60 \mathrm{~d}$ of ripening for further analysis. We quantified the oxytetracycline residues in the cheeses using liquid chromatography tandem mass spectrometry validated at the Instituto Lactológico de Lekunberri (Lekunberri, Pamplona, Spain) as previously described by Quintanilla et al. (2019). Volatile compounds analysis of the cheese samples was performed using headspace solid-phase microextraction (SPME)-GC/MS. For the SPME of volatile compounds, we followed the method developed by Hettinga et al. (2008). From each cheese, 2 samples were taken at a depth of $1 \mathrm{~cm}$ from the rind. For headspace extraction, $1 \mathrm{~g}$ of a finely grated cheese sample was weighed in $10-\mathrm{mL}$ glass headspace GC vials $(46 \times 22.5 \mathrm{~mm})$ and sealed with a $20-\mathrm{mm}$ silicone/ PTFE cap (Grace, Albany, OR). Extraction of volatile compounds by SPME was carried out using a $75-\mu \mathrm{m}$ Carboxen-polydimethylsiloxane SPME fiber (Supelco, Bellefonte, PA) at $45^{\circ} \mathrm{C}$ for $40 \mathrm{~min}$ using an autosam- pler. A vial filled with air was used as a blank. For GC/ MS analysis, the SPME fiber was desorbed for $10 \mathrm{~min}$ in the $\mathrm{GC}$ injection port at $225^{\circ} \mathrm{C}$. We performed $\mathrm{GC} /$ MS analysis using a Trace GC Ultra connected to a DSQ II mass spectrometer (Thermo Scientific, Austin, TX) and a Stabilwax-DA polyethylene-glycol column (30 m length, 0.32-mm internal diameter, $1-\mu \mathrm{m}$ film thickness; Restek, Bellefonte, PA). The oven temperature was maintained at $40^{\circ} \mathrm{C}$ for $3 \mathrm{~min}$, and then increased to $220^{\circ} \mathrm{C}$ at a rate of $15^{\circ} \mathrm{C} / \mathrm{min}$. When the final temperature of $220^{\circ} \mathrm{C}$ was reached, it was maintained for 1 min. Helium was used as a carrier gas, which was fed at a constant flow rate of $1.5 \mathrm{~mL} / \mathrm{min}$. The MS ion source was maintained at $225^{\circ} \mathrm{C}$. The MS scans were collected in full scan mode, using a mass range of 33 to $250 \mathrm{~m} / \mathrm{z}$, with the electron impact mode at $70 \mathrm{eV}$. Each compound was identified using AMDIS software with the National Institute of Standards and Technology/ Environmental Protection Agency/National Institutes of Health database (National Institute of Standards and Technology, Gaithersburg, MD) and an in-house library (Hettinga, 2009). We used Metalign and MetalignID (http://www.metalign.nl, Wageningen, Netherlands) software packages for noise reduction, peak selection, peak identification, and peak integration. We used a mixed-model ANOVA to evaluate the effects of the oxytetracycline concentration in raw milk $(0,50,100$, and $200 \mu \mathrm{g} / \mathrm{kg})$ and the ripening time $(0,15,30,45$, and $60 \mathrm{~d}$ ), as well as their respective interaction (concentration $\times$ time) on the volatile profile of the cheeses. We performed statistical analysis using Proc Mixed in SAS (version 9.2; SAS Institute Inc., Cary, NC). We used least significant difference test for multiple comparisons of the mean values. We performed multivariate analysis of the data using principal component analysis with Unscrambler X.10 software (Camo ASA, Oslo, Norway).

Cheesemaking from raw goat milk containing oxytetracycline close to MRL led to antibiotic residues in the cheeses (Figure 1). Our findings indicated that this antibiotic was widely transferred from milk to cheese, because the oxytetracycline concentration in the cheeses just before maturation (d 0) was about 4 times higher than the concentration in the raw milk used for cheese production (0.5 MRL: $3.9 \pm 0.81$; 1 MRL: $4.3 \pm 0.32$; 2 MRL: $3.5 \pm 0.57$ ). High concentration factors (3.8 to 5.7) have also been reported by Cabizza et al. (2017) and Gajda et al. (2018) when assessing the transfer of oxytetracycline from sheep and cow milk to cheese, respectively. The high fat affinity of this substance and its ability to form stable chelates with animal proteins (Giguère, 2013) could explain the high residual drug concentration in the experimental cheeses. As shown in Figure 1, the residual amounts of oxytetracycline 


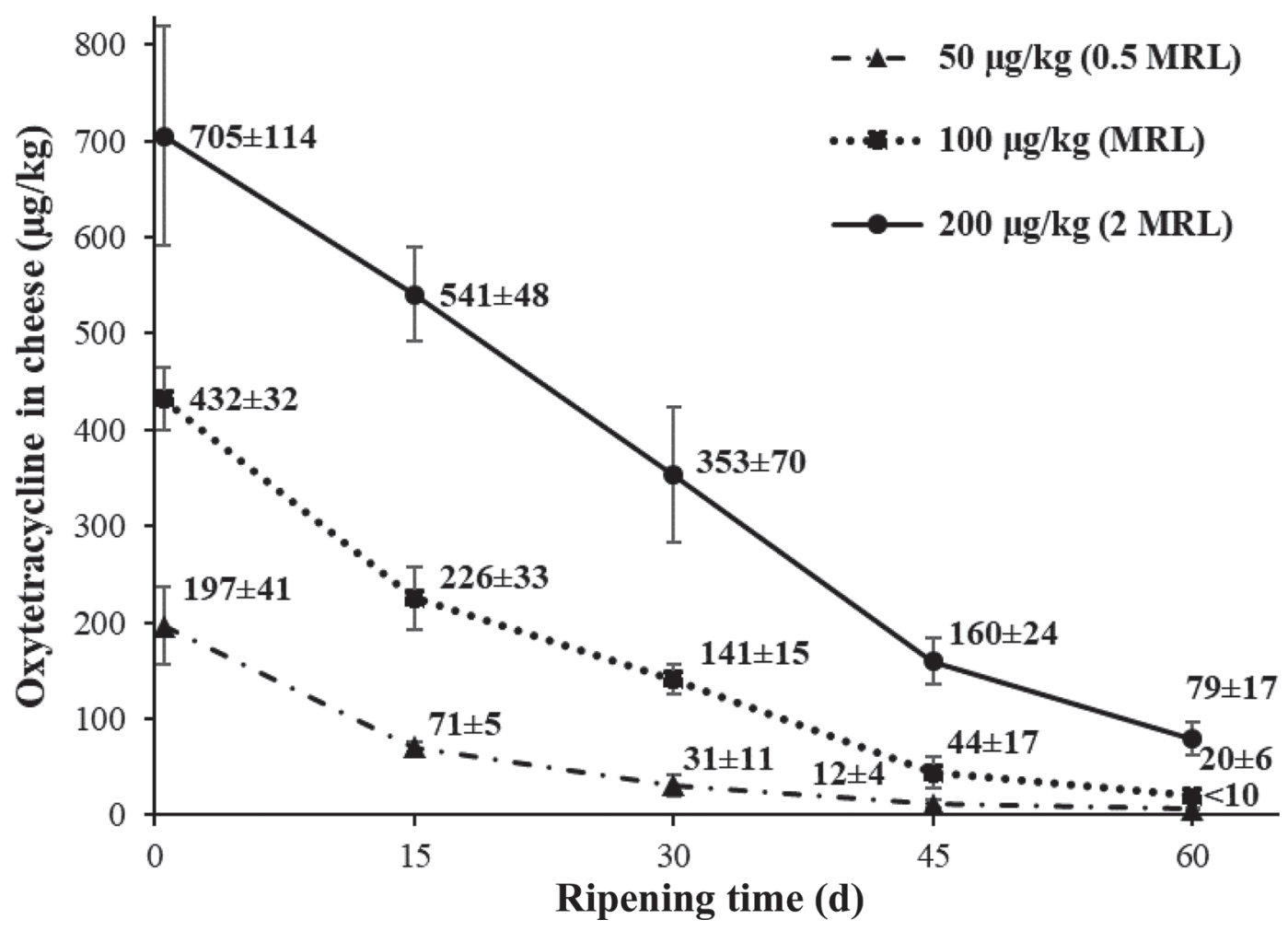

Figure 1. Antibiotic residues during ripening (mean $\pm \mathrm{SD}$ ) in Tronchón cheese made from goat milk spiked with different concentrations of oxytetracycline. $\mathrm{MRL}=$ maximum residue limit.

progressively decreased during maturation $(P<0.001)$ and was 88.8 to $96.5 \%$ lower in cheeses ripened for 60 d. Oxytetracycline is considered unstable, because its chemical structure contains 4 connected benzene rings with multiple ionizable functional groups, and under abiotic conditions it generates degradation products via epimerization, dehydration, or other pathways (HallingSørensen et al., 2003). The slightly acidic pH of the cheeses ( 5 to 5.5 ) and the environmental conditions of the maturation chamber (ambient temperature 10 to $12^{\circ} \mathrm{C}$; relative humidity 80 to $85 \%$ ) may have promoted the abiotic degradation of the oxytetracycline. Loftin et al. (2008) indicated that the degradation rate of aqueous solutions of oxytetracycline showed a positive correlation with temperature, and that oxytetracycline degrades more quickly at $\mathrm{pH} 5$ than other antibiotics. In contrast, although tetracyclines have not been documented to undergo considerable microbial degradation, the highest enzymatic activity (proteolytic and lipolytic) in the cheeses during ripening could act synergistically with environmental conditions, leading to lower residual concentrations over time. Although variable amounts of oxytetracycline were present in the cheeses over the maturation period, our findings suggest that such residues were not able to significantly affect the main biochemical pathways that produce aromatic compounds during maturation, because the volatile profile of the cheeses was unaffected by the presence of the antibiotic in the raw milk used to make the cheese $(P>0.05)$. We identified a total of 39 volatile compounds, including acids, alcohols, aldehydes, esters, ketones, and others; volatile carboxylic acids (36.3 to $66 \%$ ) and ketones (61.4 to $25.8 \%$ ) were the most abundant compounds in the volatile fraction of the Tronchón cheeses, similar to reports from Delgado et al. (2011) and Padilla et al. (2014) in other ripened goat milk cheeses.

Regarding the effect of the ripening time, statistical analysis showed that volatile profile values were modified throughout maturation (Table 1). In general, the total amounts of volatile organic acids, alcohols, and esters increased over the first $45 \mathrm{~d}$ of maturation ( $P$ $<0.001$ ), whereas ketones (the group with the highest concentrations in the first 2 wk of ripening) progressively decreased $(P<0.001)$ over the same period, possibly due to a reduction of these compounds into secondary alcohols (Andiç et al., 2015). In the last 2 weeks of maturation, we observed only minor changes, likely related to the potential lower microbial activity in the cheeses at this stage, as reported by other authors 
Table 1. Effect of ripening time on volatile compounds $\left(\mathrm{AU} \times 10^{5}\right.$, where $\mathrm{AU}=$ arbitrary units $)$ in Tronchón goat cheese ${ }^{1}$

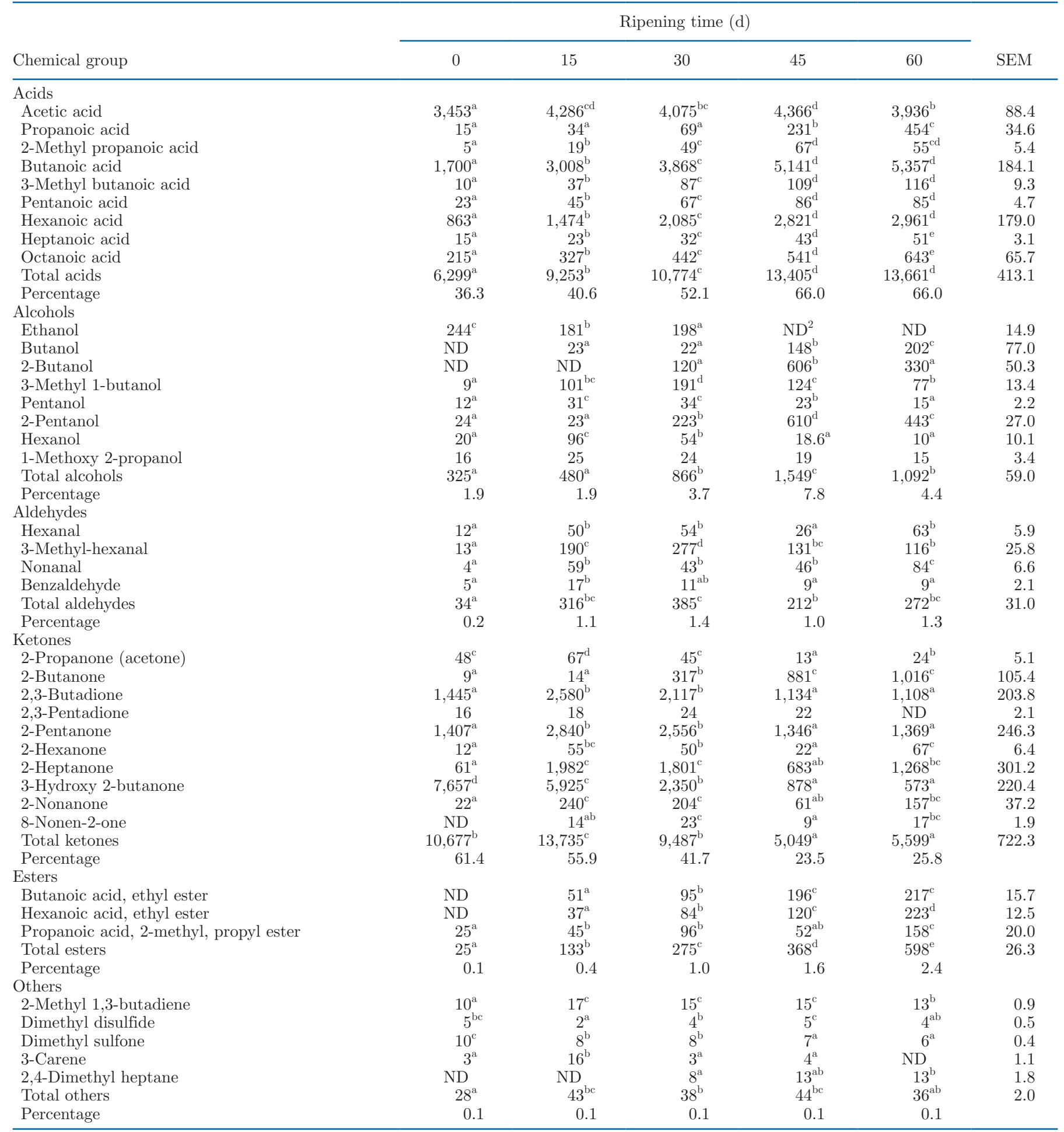

${ }^{\mathrm{a}-\mathrm{e}}$ Means with different superscripts in the same row differ significantly $(P<0.05)$.

${ }^{1}$ Values are means of 6 determinations ( 2 cheeses per ripening time $\times 3$ batch replicate). Percentage indicates the percentage of that chemical group relative to the total at a given ripening time.

${ }^{2} \mathrm{ND}=$ not detected. 

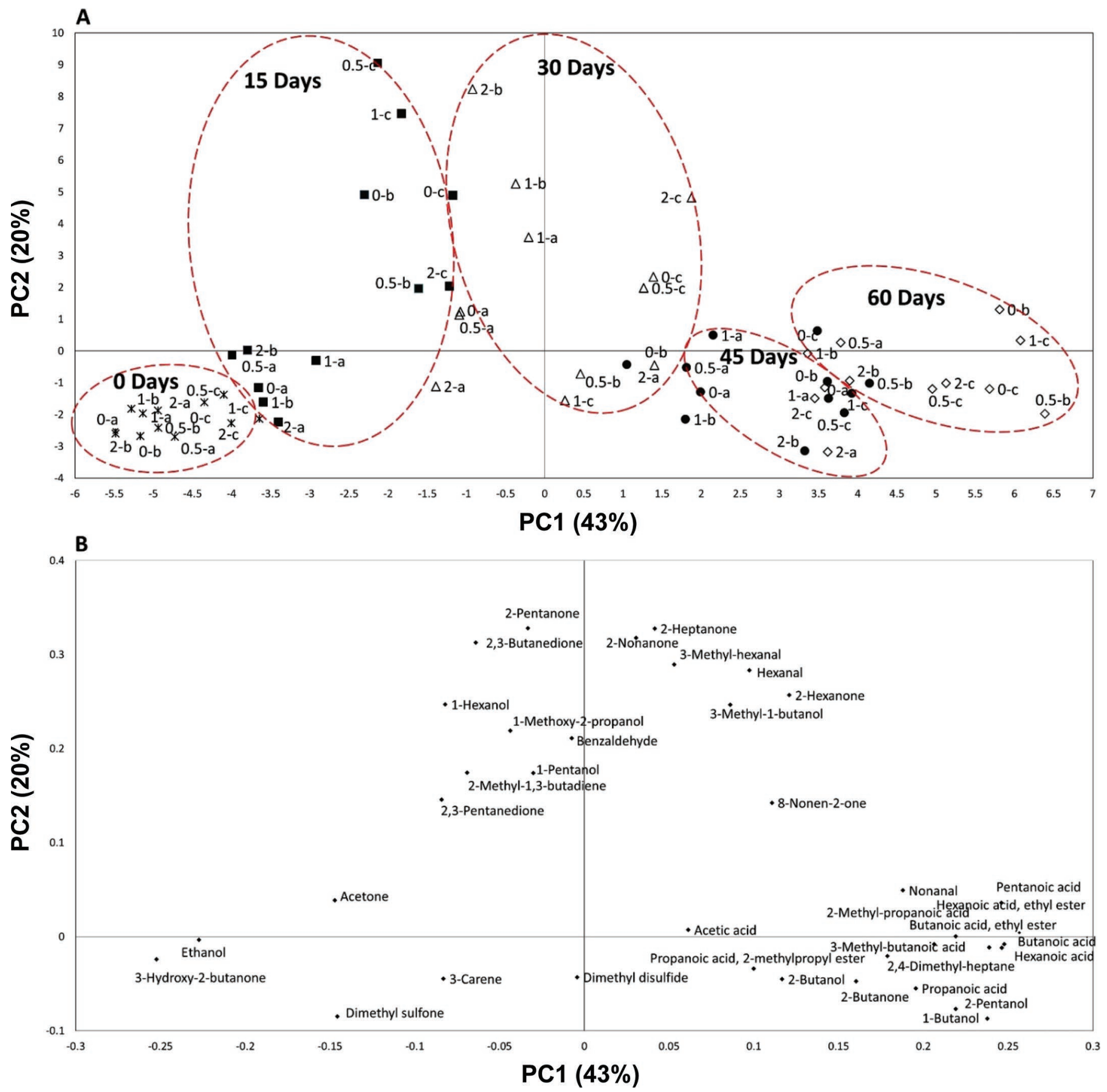

Figure 2. Score (A) and loading (B) plots for the 2 first principal components (PC1 and PC2) for the volatile profile of Tronchón cheese. The explained variances of PC1 and PC2 were 43 and 20\%, respectively. Codes in the score plots (e.g., $\Delta 1$-b) refer to the ripening time (0: *; 15: $\mathbf{\square}$; 30: $\Delta, 45: \bullet$; and $60 \mathrm{~d}: \diamond)$, the oxytetracycline concentrations in goat milk (0, 0.5 MRL, $1 \mathrm{MRL}$, and $2 \mathrm{MRL}$ ), and triplicate of cheeses manufactured for each concentration $(\mathrm{a}, \mathrm{b}$, and $\mathrm{c})$. $\mathrm{MRL}=$ maximum residue limit.

for goat cheeses with similar maturation times (Souza et al., 2003; Delgado et al., 2011). In Tronchón cheeses ripened for $60 \mathrm{~d}$, acetic, butanoic, and hexanoic acids were the most abundant volatile compounds at more than $50 \%$ of the total volatile compounds; these are typical flavor components that are perceived as a goatlike smell (Castillo et al., 2007; Delgado et al., 2011). We also detected high amounts of methyl ketones in the mature Tronchón cheese, similar to other Spanish goat cheeses such as Majorero (Castillo et al., 2007) and 
Ibores (Delgado et al., 2011). The 2-pentanone, linked to a smell described as orange peel and sweet, fruity (Curioni and Bosset, 2002), was the most important ketone along the entire maturation period. We also detected large amounts of 2,3-butanedione (diacetyl) with an intensive creamy, buttery flavor (Le Bars and Yvon, 2008). We obtained no significant interactions for almost all volatile compounds (concentration $\times$ time; $P>$ $0.05)$, suggesting that all the cheeses evolved in a similar way over time, regardless of the oxytetracycline concentration assessed. The only exception was related to some of the most quantitatively important compounds of the acid volatile fraction of the cheeses. We detected lower butanoic acid $(P<0.05)$ and hexanoic acid $(P<$ $0.01)$ content in the cheeses from goat milk containing oxytetracycline at or above MRL, especially in the first $30 \mathrm{~d}$ of ripening. We also detected lower amounts of minority volatile acids such as 3 -methyl butanoic acid $(P<0.05)$ and heptanoic acid $(P<0.05)$ during this period. The bacteriostatic activity of oxytetracycline, potentially able to produce an imbalance in the raw cheese microbiota involved in the biochemical changes during maturation (Cabizza et al., 2018), might have been responsible for the modifications of the volatile compounds.

We conducted principal component analysis to assess the overall effect of the concentration of oxytetracycline and ripening time on the volatile profile of the cheeses. We found 3 principal components to explain $70 \%$ of the variations in the data set, in which principal component 1 represented $43 \%$ of the variability and principal component 2 represented $20 \%$. Figure 2 shows the score and loading plots of the principal component analysis. In general, the presence of oxytetracycline did not have an overall effect on the volatile profile. However, the different stages of maturation were very well separated along principal component 1 , progressively from the left to the right quadrants (Figure 2). The circles represent the different stages of maturation $(0,15,30,45$, and 60 d). The loading plot shows a wider distribution of volatile compounds along principal component 1 according to ripening times, with amounts of acid compounds standing out at 45 and $60 \mathrm{~d}$ of ripening.

The presence of oxytetracycline in goat milk close to the legal maximum concentration (0.5 to $2 \mathrm{MRL}$ ) did not seem to modify the volatile profile of the Tronchón cheeses ripened for $60 \mathrm{~d}$. However, larger amounts of residues of this antibiotic could be present, especially when cheese is matured for a short time (2 to $4 \mathrm{wk}$ ). Although ripening conditions led to the degradation of residual oxytetracycline in cheese, variable amounts of this antibiotic may persist in matured cheeses, posing a risk to consumer health.

\section{ACKNOWLEDGMENTS}

This work is part of the AGL-2013-45147-R funded by the Ministry of Science and Innovation (Madrid. Spain). The authors thank the Research and Development Support Program, "Ayudas para movilidad dentro del Programa para la Formación de Personal Investigador" (2.016) of Universitat Politècnica de València (Spain), allowing Paloma Quintanilla to perform a predoctoral stay at the Food Quality and Design Group, Wageningen University and Research (Wageningen, the Netherlands). The authors state that they have no conflicts of interest.

\section{REFERENCES}

Andiç, S., Y. Tunçtürk, and G. Boran. 2015. Changes in Volatile Compounds of Cheese. V. Preedy, ed. Academic Press, Oxford, UK. https://doi.org/10.1016/B978-0-12-404699-3.00028-7.

Attaie, R., M. Bsharat, A. Mora-Gutierrez, and S. Woldesenbet. 2015. Short communication: Determination of withdrawal time for oxytetracycline in different types of goats for milk consumption. J. Dairy Sci. 98:4370-4376. https://doi.org/10.3168/jds.2014-8616.

Beltrán, M. C., R. L. Althaus, A. Molina, M. I. Berruga, and M. P. Molina. 2015. Analytical strategy for the detection of antibiotic residues in sheep and goat's milk. Span. J. Agric. Res. 13:e0501. https://doi.org/10.5424/sjar/2015131-6522.

Cabizza, R., N. Rubattu, S. Salis, M. Pes, R. Comunian, A. Paba, M. Addis, M. C. Testa, and P. P. Urgeghe. 2017. Transfer of oxytetracycline from ovine spiked milk to whey and cheese. Int. Dairy J. 70:12-17. https://doi.org/10.1016/j.idairyj.2016.12.002.

Cabizza, R., N. Rubattu, S. Salis, M. Pes, R. Comunian, A. Paba, E. Daga, M. Addis, M. C. Testa, and P. P. Urgeghe. 2018. Impact of a thermisation treatment on oxytetracycline spiked ovine milk: Fate of the molecule and technological implications. Lebensm. Wiss. Technol. 96:236-243. https://doi.org/10.1016/j.lwt.2018.05.026.

Castillo, I., M. V. Calvo, L. Alonso, M. Juárez, and J. Fontecha. 2007. Changes in lipolysis and volatile fraction of a goat cheese manufactured employing a hygienized rennet paste and a defined strain starter. Food Chem. 100:590-598. https://doi.org/10.1016/ j.foodchem.2005.09.081.

Curioni, P. M. G., and J. O. Bosset. 2002. Key odorants in various cheese types as determined by gas chromatography-olfactometry. Int. Dairy J. 12:959-984. https://doi.org/10.1016/S0958 -6946(02)00124-3.

Delgado, F. J., J. González-Crespo, R. Cava, J. García-Parra, and R. Ramírez. 2010. Characterisation by SPME-GC-MS of the volatile profile of a Spanish soft cheese P.D.O. Torta del Casar during ripening. Food Chem. 118:182-189. https://doi.org/10.1016/j .foodchem.2009.04.081.

Delgado, F. J., J. González-Crespo, R. Cava, and R. Ramírez. 2011. Formation of the aroma of a raw goat milk cheese during maturation analysed by SPME-GC-MS. Food Chem. 129:1156-1163. https://doi.org/10.1016/j.foodchem.2011.05.096.

European Union. 2010. Regulation (EU) no. 37/2010 of 22 December 2009 on pharmacologically active substances and their classification regarding maximum residue limits in foodstuffs of animal origin. Accessed Feb. 20, 2020. https://eur-lex.europa.eu/legal -content/EN/TXT/?uri=CELEX\%3A32010R0037.

Gajda, A., E. Nowacka-Kozak, M. Gbylik-Sikorska, and A. Posyniak. 2018. Tetracycline antibiotics transfer from contaminated milk to dairy products and the effect of the skimming step and pasteurisation process on residue concentrations. Food Addit. Contam. Part A Chem. Anal. Control Expo. Risk Assess. 35:66-76. https://doi .org/10.1080/19440049.2017.1397773. 
Giguère, S. 2013. Antimicrobial drug action and interaction. Pages 1-10 in Antimicrobial Therapy in Veterinary Medicine. 5th ed. S. Giguère, J. F. Prescott, and P. M. Dowling, ed. WileyBlackwell, Ames, IA. https://doi.org/https://doi.org/10.1002/ 9781118675014.ch1.

Halling-Sørensen, B., A. Lykkeberg, F. Ingerslev, P. Blackwell, and J. Tjørnelund. 2003. Characterization of the abiotic degradation pathways of oxytetracyclines in soil interstitial water using LCMS-MS. Chemosphere 50:1331-1342. https://doi.org/10.1016/ s0045-6535(02)00766-https://doi.org/x.

Hettinga, K. A. 2009. Quality control of raw cows' milk by headspace analysis, a new approach to mastitis diagnosis. PhD Thesis. Wageningen University, the Netherlands.

Hettinga, K. A., H. J. F. Van Valenberg, and A. C. M. Van Hooijdonk. 2008. Quality control of raw cows' milk by headspace analysis. Int. Dairy J. 18:506-513. https://doi.org/10.1016/j.idairyj.2007.10 .005 .

Katla, A. K., H. Kruse, G. Johnsen, and H. Herikstad. 2001. Antimicrobial susceptibility of starter culture bacteria used in Norwegian dairy products. Int. J. Food Microbiol. 67:147-152. https://doi .org/10.1016/s0168-1605(00)00522-5.

Le Bars, D., and M. Yvon. 2008. Formation of diacetyl and acetoin by Lactococcus lactis via aspartate catabolism. J. Appl. Microbiol. 104:171-177. https://doi.org/10.1111/j.1365-2672.2007.03539.x.

Loftin, K. A., C. D. Adams, M. T. Meyer, and R. Surampalli. 2008. Effects of ionic strength, temperature, $\mathrm{pH}$ on degradation of selected antibiotics. J. Environ. Qual. 37:378-386. https://doi.org/ 10.2134/jeq2007.0230.

McSweeney, P. L. H., and M. J. Sousa. 2000. Biochemical pathways for the production of flavour compounds in cheeses during ripening: A review. Lait 80:293-324. https://doi.org/10.1051/lait:2000127.
Padilla, B., C. Belloch, J. J. López-Díez, M. Flores, and P. Manzanares. 2014. Potential impact of dairy yeasts on the typical flavour of traditional ewes' and goats' cheeses. Int. Dairy J. 35:122-129. https:/ /doi.org/10.1016/j.idairyj.2013.11.002

Quintanilla, P., M. C. Beltrán, A. Molina, I. Escriche, and M. P. Molina. 2019. Characteristics of ripened Tronchón cheese from raw goat's milk containing legally admissible amounts of antibiotics. J. Dairy Sci. 102:2941-2953. https://doi.org/10.3168/jds.2018-15532.

Sierra, D., A. Contreras, A. Sánchez, C. Luengo, J. C. Corrales, C. T. Morales, C. De la Fe, I. Guirao, and C. Gonzalo. 2009. Short communication: Detection limits of non- $\beta$-lactam antibiotics in goat's milk by microbiological residues screening tests. J. Dairy Sci. 92:4200-4206. https://doi.org/10.3168/jds.2009-2101.

Souza, C. F. V., T. Dalla Rosa, and M. A. Z. Ayub. 2003. Changes in the microbiological and physicochemical characteristics of Serrano cheese during manufacture and ripening. Braz. J. Microbiol. 34:260-266. https://doi.org/10.1590/S1517-83822003000300016.

\section{ORCIDS}

P. Quintanilla () https://orcid.org/0000-0003-0422-1903

K. A. Hettinga @ https://orcid.org/0000-0002-9017-4447

M. C. Beltrán () https://orcid.org/0000-0002-5335-2179

I. Escriche $\odot$ https://orcid.org/0000-0003-0180-0360

M. P. Molina ๑ https://orcid.org/0000-0002-0647-8609 